\title{
Os seluagens de Nuremberg e o seu lamento pela imprensa de 1545
}

The savages of Nuremberg and their lament in the press of 1545

Luciana Villas Bôas

Universidade Federal do Rio de Janeiro, Rio de Janeiro, RJ, Brasil

Para Guenther Roth

Resumo: Este artigo discute a representação de uma família de selvagens no panfleto intitulado "O Lamento dos selvagens da floresta sobre um mundo desleal" (Nuremberg, 1545). A partir das fontes iconogáficas e textuais às quais remontam a xilogravura de Hans Schäufelein e o poema de Hans Sachs, o artigo explora sentidos específicos da selvageria antes da sua moderna oposição à noção de civilização. Atém-se à função especular dos selvagens, isto é, à sua condição de indígenas alemães, asselvajados por opção. Argumenta que os selvagens alemães não apenas reatualizam o primitivismo clássico, mas também apresentam reinvidicações protestantes. A radicalidade da crítica social que corporificam e articulam está ligada à emergência de "espaços livres ideais" no âmbito de uma incipiente esfera pública na Alemanha da Reforma.

Palavras-chave: Selvageria. Conceito e iconografia. Hans Schäufelein. Hans Sachs. Imprensa. Esfera pública.

Abstract: This article discusses the representation of a family of savages in a pamphlet titled "Lament of the Wild Forest Folk over the Perfidious World" (Nuremberg, 1545). Based upon iconographical and textual sources, from which Hans Schäufelein's woodcut and Hans Sachs's poem derive, the article explores specific meanings of savagery before its modern opposition to the notion of civilization. It dwells upon the specular function of the savages, i.e., their condition as indigenous Germans, who chose to become a wild folk. It argues that the German savages not only refashion classical primitivism, but also convey Protestant demands. The radicalness of the social critique they embody and articulate bears upon the emergence of "free ideal spaces" within an incipient public sphere in Protestant Germany.

Keywords: Savagery. Concept and iconography. Hans Schäufelein. Hans Sachs. Printing press. Public sphere. 


\section{"Lamento dos selvagens da floresta sobre o mundo desleal"}

Luciana

Villas Bôas

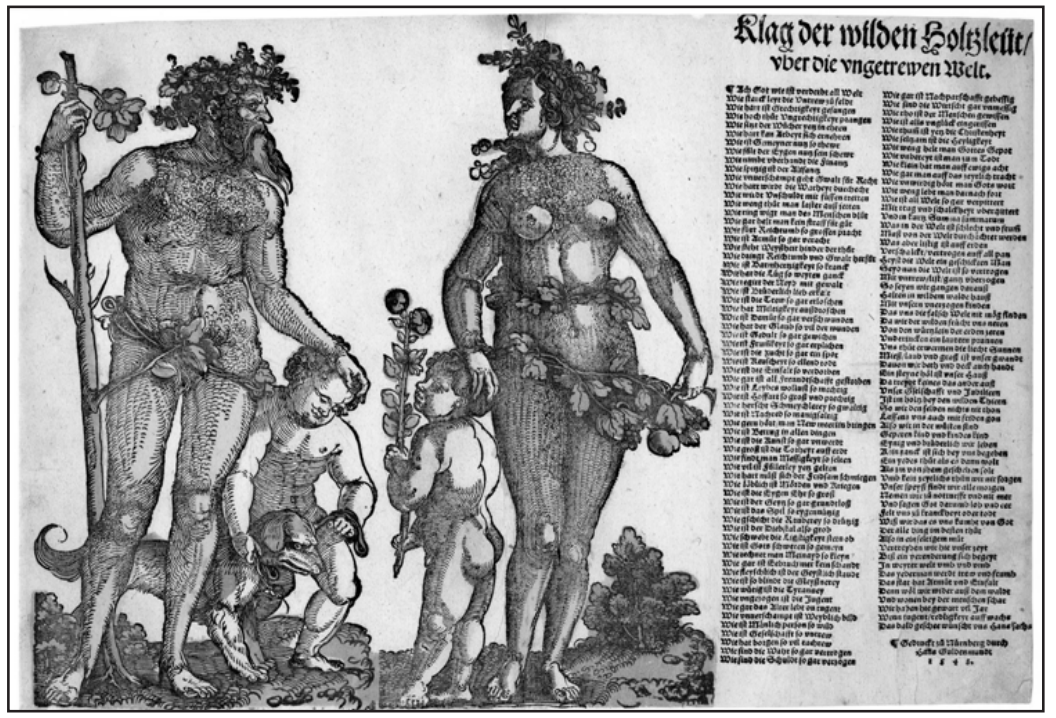

Fonte: The British Museum.

A espectadora do panfleto hesita. À esquerda enxerga um casal e seus filhos, à direita um texto versificado. Primeiro contempla a imagem. As figuras, nuas e neoclássicas, habitam uma paisagem amena. Os gestos revelam brandura. São pura reciprocidade. $\mathrm{O}$ homem e a mulher têm o olhar voltado na direção um do outro, as mãos pousadas na fronte dos filhos. Um das crianças segura um cão, a outra um ramo florido. A família aparece entrelaçada suavemente por galhos frondosos; a natureza é complacente. $O$ teor da cena é árcade, edênico, ou os dois. Ao avistar o título, a espectadora, agora leitora, percebe que a família é de "selvagens, habitantes da floresta" (wilde Holzleüt) e os versos, a entoação de um "lamento" (Klag). O lamento, anunciado em letras garrafais, é sobre um "mundo desleal" (ungetrewe welt): "Ó deus, como o mundo se corrompeu", dispara o primeiro verso. ${ }^{1} \mathrm{O}$ último verso da longa sequência de dísticos revela o nome do autor, o poeta Hans Sachs, o lugar e a data de impressão do folheto, Nuremberg, 1545.

O panfleto dos selvagens de Nuremberg é a prova estampada de uma mudança de perspectiva. Como os selvagens poderiam expor os

1 Todas as traduções de originais alemães são minhas. 
vícios dos seus contemporâneos se não fossem eles próprios reputados virtuosos? É a condição meritória do selvagem que autoriza o seu “lamento". Mas quem são, afinal, esses selvagens? Será que o seu lamento acarreta o elogio da selvageria? Qual a noção de selvageria que se materializa nesses selvagens refugiados na floresta por oposição deliberada a um "mundo" vicioso? Serão asselvajados? E, nesse caso, seriam todos os seres humanos vulneráveis ao asselvajamento? Parece haver no século XVI uma semântica cultural atravessada por uma distinção aconceitual, avant la lettre, entre o que modernamente se cristalizaria como a oposição entre "natureza" e "cultura", "selvageria" e "civilização". Se o panfleto articula a "selvageria" sem o contraponto do termo "civilização", por onde devemos começar? Gostaria de começar pela figura do "homem selvagem", a partir de fontes iconográficas e textuais.

Os selvagens de Nuremberg e o seu lamento pela imprensa de 1545 A gravação dos selvagens de Nuremberg foi realizada originalmente em 1530, possivelmente ligada à composição do poema de Sachs, escrito em 2 de junho $1530 .^{2}$ Essa circunstância, no entanto, não esgota os sentidos da imagem, cujo vocabulário próprio a faz interagir com o componente textual do panfleto.

\section{Do isolamento à socialização: a metamorfose do selvagem}

Um dos traços mais flagrantes da iconologia do selvagem são os pelos que lhe cobrem o corpo, ao mesmo tempo ocultando e expondo a sua nudez. Ao longo de toda a Idade Média, homens e mulheres selvagens aparecem, invariavelmente, como seres cujos pelos e cabeleiras são abundantes. ${ }^{3}$ A visão do selvagem hirsuto era de tal modo estabelecida que o cosmógrafo franciscano André Thevet dedicou um capítulo inteiro das Singularités de la France Antarctique (Paris, 1557) para demonstrar que os selvagens "não são peludos". A nudez vicejante dos selvagens dava a ver a sua sujeição irrestrita à natureza. Pensadores antigos e medievais consideravam os selvagens seres dominados pelas paixões, incapazes de controlar os seus afetos, notoriamente instáveis e hostis ao resto da humanidade. ${ }^{4}$ Solitários, incapazes de constituir família,

\footnotetext{
2 A justaposição das imagens de Schäufelein e do poema de Sachs no panfleto de 24 x $32 \mathrm{~cm}$ é obra da tipografia de Hans Goldenmundt, um especialista em Einblattdrucke, folhetos avulsos de uma página. Ver Benzing (1982, p. 356-357).

3 "The convention of hair, as well as much of the wild man's nature, can be traced to his ancient ancestors in pagan mythologies and the interpretation given to them by medieval men." (HUSBAND, 1980, p. 10).

4 Sobre personificações da morte, da loucura e da selvageria na iconografia renascentista
} 
Luciana Villas Bôas

ligam-se, às vezes, a uma companheira, mas abandonam os filhos no caminho. $O$ desgoverno dos selvagens os condena a ser nômades, itinerantes de regiões não domesticadas, como desertos, florestas e montanhas (WHITE, 1978, p. 153). O isolamento do homem selvagem, a sua misantropia persistente, corresponde ao fato de ele ser destituído de linguagem. Os selvagens são solitários, genuinamente, porque não sabem falar (RUBIÉS, 2011, p. 99). A ausência de linguagem é, ao lado da "nudez" física e moral, uma constante da selvageira, uma obstinação que se estende de Lucrécio a Rousseau. A selvageria medieval não era uma prerrogativa masculina; mulheres selvagens e ferozes também espreitavam as florestas. Mas com uma diferença: embora os homens selvagens fossem frequentemente capturados e amansados por damas (WHITE, 1978, p. 167; BERNHEIMER 1952, p. 125), não há imagens correspondentes de cavalheiros aptos a domar mulheres selvagens.

Essa breve revisão da iconologia dos selvagens durante a Idade Média traz à tona os aspectos desviantes dos selvagens de Nuremberg. Nossos selvagens não estão sós, ou em hordas, mas amorosamente em família. Não habitam uma natureza inóspita, cultivam um jardim. Não são nômades, muitos menos ferozes como alguns predecessores, canibais ou lobisomens. Não são hostis à humanidade, são misantropos por amor ao mundo. Não só tem o dom da linguagem, como sabem cantar o seu lamento em versos. São, como os Tupinambá que Montaigne descreveu e elogiou, selvagens poetas. Os selvagens do nosso panfleto, somos levados a concluir, evocam a metamorfose do homem selvagem ocorrida, segundo estudiosos, nos séculos XIV e XV. Nesse período, o homem selvagem torna-se "objeto de admiração" (WHITE, 1978, p. 167). Trata-se para alguns de uma "rehabilitação do homem selvagem" (WHITE, 1978, p. 174), porque associada à recuperação da cultura clássica antiga, em particular de figuras pagãs libertárias (faunos, centauros, sátiros) e do primitivismo clássico (o culto a um estágio idílico da humanidade, a Idade de Ouro). Especula-se ainda que os selvagens percam o seu prestígio de mito e passem a desempenhar funções simbólicas. $\mathrm{O}$ seu deslocamento dos confins do mundo para a periferia das cidades sinalizaria uma mudança na concepção de selvageria, que se transformaria em condição intrínseca de toda a humanidade

enquanto figuras de alteridade associadas às contradições do desejo sexual, ver Christian Kiening (2003, p. 128-132). 
(HUSBAND, 1980, p. 12). Trata-se, em outras palavras, da modernização do selvagem, dos primórdios de uma semântica em que se opõem natureza e cultura.

Seja como for - mais adiante retomaremos essas interrogações -, a mudança valorativa na imagem dos selvagens é notável pelo seu entorno: os selvagens abandonam a selva para habitar paisagens árcades. Transformam-se, ao mesmo tempo, em seres regulares, capazes de arar o campo e de cuidar da família (HUSBAND, 1980, p. 30-31). A harmonia dos selvagens de Nuremberg tem alguns precedentes visuais. Em 1500, surgem imagens de selvagens habitantes de bosques em cujo fundo se avista a cidade: o trio beatífico formado pelo pai, a mãe e o recém-nascido evoca representações da sagrada família. Significativamente, é nesse período que surgem as primeiras imagens dos selvagens do Novo Mundo na Europa, em geral produzidas em territórios de língua alemã. Entre essas imagens, merecem destaque as xilogravuras do artista Hans Burgkmair. Residente na cidade imperial de Augsburg, Burgkmair foi um dos arquitetos do imenso conjunto de xilogravuras impressas, o triunfo do imperador Maximiliano I, realizado entre 1512 e 1519. Um dos blocos atribuídos a Burgkmair mostra um grupo de índios Tupinambá portando armas e vestindo roupas e adereços plumários característicos. Os Tupinambá participam do cortejo não na condição de cativos, mas na de súditos, em pé de igualdade com os demais povos (LEITCH, 2010, p. 153). Outro renomado artista, também colaborador do Triunfo, Albrecht Dürer, atuante em Nuremberg, a cidade imperial vizinha, desenharia em 1515 um guerreiro Tupinambá, cuja minúcia etnográfica espanta ainda hoje (STURTEVANT, 1978, p. 423). A comparação das imagens sugere que Burgkmair e Dürer buscaram inspiração nos mesmos objetos e relatos do além-mar que circulavam na corte de Maximiliano I.

Hans Schäufelein, o gravurista cujo monograma aparece nas impressões originais do homem e da mulher selvagens (1530) que seriam usadas no panfleto de Nuremberg (1545), conviveu diretamente com os artistas responsáveis pelos primeiros registros visuais dos habitantes do Novo Mundo. Com base em sua biografia, é mais do que provável que Schäufelein tenha admirado imagens dos Tupinambá, escutado descrições e admirado objetos do continente recém-descoberto. Trabalhou em Nuremberg, na oficina de Dürer (1504-1507), e em seguida em Augsburg, na oficina de Hans Holbein, o Velho (1508-1512). Viveu intensamente o ambiente cultural que reunia artistas e letrados das duas 
grandes cidades imperiais. Para se ter uma ideia da sua rede de relações, basta dizer que um dos membros ilustres era Conrad Celtis, poeta laureado, bibliotecário de Maximiliano I e mentor do diálogo entre artistas e humanistas. ${ }^{5}$ Celtis não foi apenas um grande propagador do humanismo clássico em terras alemãs; foi sobretudo um laborioso intérprete de um texto romano, cujo apelo atingiria em cheio os selvagens do panfleto de 1545: a Germania de Tácito.

Antes de nos determos no poema do Sachs, e em outros textos que nele repercutem, tentemos recapitular o apelo visual dos selvaLuciana gens. Antes de mais nada, frisemos a precocidade dos bons selvagens de Nuremberg. Somente em 1590, sessenta anos após a composição das xilogravuras, surgiriam os selvagens de Théodor de Bry, figuras edênicas e árcades, comparáveis aos de Schäufelein. Contudo, a representação etnográfica dos selvagens da Virgínia e a sua localização em uma colônia na América do Norte contrastam com o despojamento clássico e o ambiente familiar dos selvagens de Nuremberg. Os selvagens de Schäufelein são sucessores das famílias de selvagens que irrompem no imaginário antropológico no início do século XVI; não têm a precisão etnográfica dos desenhos de Dürer ou Burgkmair nem o exotismo convencional de rústicos europeus ou americanos. Contudo, as imagens idílicas de famílias selvagens anteriores à do panfleto de Nuremberg são escassas, de circulação limitada, e, ainda que os seus protagonistas tivessem o dom da linguagem, eles não falam, ou pelo menos não se dirigem diretamente a um público, em 128 versos. Como explicar essa combinação inusitada de selvagens eloquentes? A resposta nos conduz à reintrepretação de um texto clássico no humanismo renascentista alemão.

\section{o espelho indígena no humanismo renascentista e na literatura volante}

O autor responsável por dar a palavra aos selvagens chama-se Hans Sachs. Os epítetos de sapateiro, poeta, mestre-cantor, dramaturgo e reformador protestante definem o seu lugar no cânone literário. Autor do poema "O rouxinol de Wittenberg" (Nuremberg, 1523), dedicado à doutrina de Martinho Lutero, Sachs foi um militante da nova confissão.

5 Celtis escreveu um epigrama em louvor a Albrecht Dürer. Ver <http://duererforschung.gnm.de/ celtis-epigramme-78-100/>. Sobre a colaboração entre Celtis, Dürer e Burgkmair ver Dieter Wuttke (1985). 
Mestre-cantor e autor de folias de carnaval, escreveu diversos gêneros poéticos e interviu na sua fortuna crítica ao editar em 1558 as suas obras. Nesta edição, classifica os seus "lamentos" entre escritos variados, que incluem histórias, polêmicas, elogios, fábulas e diálogos jocosos (histori, kampffgesprech, gesprech, lobspüch, klagred, sprüch, fabel und schwenck apud KÖNNEKER, 1971, p. 38-39). O "Lamento dos selvagens da floresta sobre o mundo infiel" ecoa outros "lamentos" (Klag) ou "discursos lamentosos" (Klagrede) que Sachs circulava em folhetos pela imprensa.

Os lugares-comuns que se repetem nos "lamentos" saltam à vista: a floresta inabitada como lugar de refúgio da corrupção do clero e dos cidadãos, a generalização da corrupção que atinge todos os estamentos, a tal ponto avançada que o mundo em pessoa, a dona Mundo (Frau Welt), lamenta a sua própria degradação. Este último folheto, "Lamento do

Os selvagens de Nuremberg e o seu lamento pela imprensa de 1545 mundo [...]", publicado em Nuremberg, em 1531, pode ser lido como um texto complementar ao "Lamento dos selvagens". Afinal, o mundo, do qual os selvagens se refugiaram, personifica-se nele, inconfundível, na figura de uma mulher. Luxuosa e afetada, a dona Mundo é o oposto da simplicidade e da virtude dos selvagens. Os panfletos dos selvagens e do mundo formam um dueto: são uma justaposição da natureza humana e da sua irrefreável corrupção. Mas os folhetos também se associam temporalmente. $\mathrm{O}$ interlocutor que se encarrega de instruir e contabilizar os vícios da dama, a dona Mundo, admite que houve um passado remoto durante o qual ela foi bem governada: "Antes eras chamada mundo de ouro, pois sabias bem conduzir o humano governo" ("Vor warst die gulden welt genent/Fürst doch gut menschlich regiment”, SACHS, 1531, $\mathrm{s} / \mathrm{p})$. A diferença temporal entre o mundo e os selvagens é antes de tudo política, diz respeito ao modo de governo e supõe que a selvageria é uma condição virtual, à qual é possível retroceder: abandonando o mundo, despindo-se dos seus artifícios. Na literatura volante, a selvageria não é perda, mas recuperação da humanidade. Eis por que os selvagens são contemporâneos.

A simplicidade e a integridade moral dos "selvagens" são uma marca indelével do projeto patriótico-nacionalista que abarca toda a obra do humanista Conrad Celtis. Celtis adaptará o modelo do primitivismo clássico para construir a imagem do ancestral germânico como bárbaro virtuoso. Em 1500, Celtis publica a sua edição comentada e ampliada da Germania de Tácito. Apesar de não ser o primeiro letrado alemão a recorrer ao texto, e muito menos o seu primeiro editor, consegue 
Luciana Villas Bôas

despertar um fascínio sem precedentes e transformar a interpretação do texto em uma disputa fatídica. ${ }^{6}$ Celtis desejava que todas as suas obras viessem a integrar o inacabado projeto intitulado Germania illustrata - a exemplo da Italia illustrata de Flavio Biondo. O ímpeto nacionalista atravessa toda a sua obra poética, das primeiras odes inspiradas em Horácio às elegias reunidas sob o título Amores, em alusão à obra homônima de Ovídio, e publicadas em 1502, em Nuremberg. Na dedicatória a Maximiliano I, Celtis afirma que a "descrição da pátria" é o seu interesse maior (HUBER-REBENICH, 2006, p. 59-60). ${ }^{7}$ A motivação patriótica já aparece na divisião da coletânea: cada uma das sequências é dirigida a uma amada, cada amada personifica uma região da Alemanha. Além disso, vários poemas dos Amores, sobretudo "Ad Elsulam", são verdadeiros atalhos da interpretação que Celtis deu à Germania de Tácito. ${ }^{8}$

Escrito no final do século I (cerca de 98 d.c.), Germania é uma etnografia dos povos germânicos imaginados como uma "nação". Os "germânicos" seriam habitantes originais, "indígenas" de um mesmo território, facilmente localizáveis, unidos por consanguinidade, de hábitos comuns e organização política coesa (TÁCITO, 1988, p. 70). Essa unidade geográfica e étnica do texto de Tácito alimentou a identificação imaginária entre os alemães e os antigos povos germânicos ao longo da história (KREBS, 2005a, p. 56). Já a unidade fictícia é o pressuposto comum das interpretações dos editores da Germania: seja da barbarização dos povos germânicos por Enea Silvio Piccolomini, da sua reabilitação por Giannantonio Campano ou da sua idealização por Celtis. Controverso ao longo de negotiatio Germaniae é em que medida Tácito deve ser lido como laudator Germanorum, um elogiador dos germânicos (KREBS, 2005a, p. 26-33).

Não podemos explorar aqui o quão ambivalente é a imagem que Tácito pinta dos "germânicos". Já se demonstrou que o próprio Tácito ocasionalmente reconheceu a "admirável diversidade dos germânicos"

\footnotetext{
6 Sobre a história de longa duração do "ancestral germânico", da sua invenção no renascimento humanista e da sua monumentalização no nacional-socialismo, ver Christopher B. Krebs (2011) e Ride (1977).

7 "Der Band enthält neben den Elegien unter anderem auch das zur Verherrlichung des Kaisers dienende höfische Festspiel Ludus Dianae, das hexametrische Gedicht Germania generalis und eine Beschreibung der Stadt Nürnberg in Prosa, den Libellus de origine, situ, moribus et institutis Norimbergae. Celtis verstand diese Werke als Vorarbeiten zu seiner geplanten Germania illustrata, einer umfassenden kulturellen und geographischen Beschreibung Deutschlands" (HUBER-REBENICH, 2006, p. 60).

8 Krebs escreve com razão que, embora Celtis tenha recorrido a inúmeros outros textos antigos, “[...] Germania deve ser considerada a sua obra de referência principal." (KREBS, 2005b, p. 196).
} 
(mira diversitas Germanorium) e que a sua imago Germaniae ensejou interpretações diversas e igualmente tendenciosas (KREBS, 2005a, p. 8185). ${ }^{9}$ Essencial ao nosso argumento é sublinhar que Tácito instrumentaliza o elogio dos selvagens longínquos para fazer a crítica dos romanos do seu tempo. As qualidades maiores atribuídas aos povos germânicos, a simplicidade, a liberdade e a virtude (simplicitas, libertas, e virtus), espelham as dos antigos romanos e, ao mesmo tempo, denunciam a corrupção moral do presente. Essa função especular das descrições está relacionada ao público de aristocratas romanos a quem se dirige o texto e ao período posterior às guerras dácias: “Após as instabilidades do governo de Domiciano, Tácito quis trazer novamente à tona os três exempla maiorum [simplicitas, libertas, virtus]" (KREBS, 2005a, p. 82).

A função especular do selvagem é um dos elementos principais da

Os selvagens

de Nuremberg e o seu lamento pela imprensa de 1545 fonte latina a que Celtis recorre para compor o seu elogio dos ancestrais germânicos. Celtis amplia a função do selvagem como espelho no poema "Ad Elsulam a priscis et sanctis Germaniae moribus degenerantem" (Amores II, 9); a enumeração dos vícios, e virtudes correspondentes, dá a medida da degradação do presente (KRAPF, 1979, p. 73). A oposição entre corrupção moral e integridade se materializa nas imagens de Elsula no presente e dos indígenas no passado. A pompa e a extravagância das roupas de Elsula, os gestos afetados e até obscenos contrastam com a simplicidade, a pureza e a fidelidade conjugal dos "germânicos". É fácil perceber como em "Ad Elsula" reverbera a etnografia da Germania. Menos óbvio, mas imprescindível para nós, é reconhecer a imagem dos antigos "germânicos" (imago Germaniae veteris) no "Lamento da dona Mundo" e no "Lamento dos selvagens".

\section{o primitivismo clássico/protestante dos selvagens alemães}

O poema de Sachs divide-se em duas partes. A primeira, dos versos 1 a 86 , é um catálogo de vícios e virtudes. A simplicidade se opõe ao luxo, a fidelidade à luxúria, a liberdade à necessidade etc. A segunda, dos versos 87 a 128, faz a autobiografia dos selvagens e o elogio da simplicidade. A descrição do mundo corrompido é a razão de ser dos selvagens que dele se desgarraram. A palavra "wild" (wilt) aparece pela primeira

9 "Primitivität, die Tacitus einmal unter positive, einmal unter negativen Vorzeichen gesehen hatte, konnte entsprechend als moralische Integrität oder als Barbarei verstaden warden." (KRAPF, 1979, p. 48). 
vez no corpo do poema, na linha 62, para qualificar "a pessoa", o caráter dos homens em contraposição à "aparência desavergonhada" (unverschemt...bilt) das mulheres. $O$ adjetivo só aparece de novo na segunda parte do poema, que começa na linha 87, "desde que o mundo ficou tão dissimulado" (Seit die nun die welt ist so vertrogn) e os selvagens dele se exilaram: "para trás nós o deixamos/e a floresta selvagem habitamos" (so seien wir gangen draus/halten im wilden walde haus). Como os selvagens se lamentam do mundo no plural, e o pronome correspondente em alemão é "wir" ("nós"), a sua repetição produz uma bela aliteração com

Luciana Villas Bôas "wild", "wald" e "welt" ("selvagem", "floresta" e "mundo"), o núcleo semântico do poema. 0 nós que habita a selva, e já faz muitos anos se asselvajou, permanecerá exilado até o mundo se regenerar, "que isto seja logo é o que nos deseja Hans Sachs" (das balt gescheh, wünscht uns Hans Sachs).

No panfleto, é necessário insistir, os selvagens são visíveis e, ao mesmo tempo, audíveis. O panfleto é um conjunto de técnicas - iconográficas, dramáticas e vocais - para a encenação do seu "lamento". ${ }^{10} \mathrm{~A}$ teatralidade acentuada do panfleto inclui o próprio Hans Sachs, evocado como mentor dos selvagens, ator e autor, espectador e personagem. o poeta, dissimulado-descarado, que critica o seu tempo, disfarçado de selvagem para mostrar-se idealmente nu, é uma irritante atração para a historiadora da literatura. Sachs antecipa a ficção de Montaigne ilustrada no ensaio "Dos canibais" e na concepção dos Ensaios como autorretrato. Os selvagens de Sachs fazem um autorretrato do "mundo" em 1530, etnografizam os alemães nos primórdios da Reforma Luterana, assim como os Tupinambá de Montaigne espelham a França das Guerras de Religião. Mas os Tupinambá guardam uma "maravilhosa distância" em relação ao "nós" no ensaio de Montaigne. Os selvagens de Sachs são, ao contrário, indígenas alemães. São declaradamente asselvajados, não por naufrágio ou cativeiro, mas por deliberação. Tomados da iconografia religiosa e etnográfica, revelam qualidades edênicas e ameríndias. ${ }^{11}$ Mas neles essas qualidades convergem para fazer sobressair o seu primitivismo clássico de selvagens alemães.

O letrado humanista da época logo teria reconhecido nos selvagens contemporâneos os atributos dos antigos e veneráveis "germânicos".

10 Sobre o caráter interativo e escultural de impressos quinhentistas, ver Susanne Karr Schmidt (2006).

11 Sobre a inspiração edênica, pré-lapsária, de Sachs e Schäufelein, ver Kathleen M. Crowther (2010). 
A matriz da nova imaginação histórica, a Germania de Tácito, mesmo lida de relance, não deixa dúvida em relação a referências do "Lamento dos selvagens" à fonte clássica: a condição de silvícolas, isolados na floresta, que se abrigam em cavernas (SACHS, linhas 90-99; TÁCITO, p. 82-83); cujas "crianças crescem nuas e sujas" (TÁCITO, p. 86-87), “as nossas crianças malcriadas" (SACHS, linha 92); o fato extraordinário de serem bárbaros monogâmicos, pudicos e fiéis (TÁCITO, p. 84-85; SACHS, linha 55). São muitas as alusões de Sachs aos antigos "germânicos". No entanto, uma delas é chave para se compreender a aparição dos selvagens do presente: os antigos "germânicos", incapazes de dissimulação, revelavam tudo que seu coração ocultasse; nada mais fácil do que "desnudar" as suas opiniões (ergo detecta et nuda omnium mens [TÁCITO, p. 88]). Os selvagens do panfleto reencenam uma nudez original. Vi-

Os selvagens de Nuremberg e o seu lamento pela imprensa de 1545 síveis e legíveis, os selvagens que se desnudam em protesto contra a dissimulação do mundo aderem ao movimento da Reforma, ao princípio que torna a "revelação" e a "publicação" acontecimentos equivalentes, simultâneos. As palavras "revelação" (Offenbarung) e "esfera pública" (Öffentlichkeit) não têm apenas a mesma raiz: a necessidade de garantir o acesso do "homem comum" (gemeiner Mann) a toda verdade, um preceito teológico (protestante) e tecnológico (tipográfico) na Alemanha da Reforma, faz com que os conceitos se tornem convergentes. A variante do topos do "homem comum" (gemeiner Mann), "todo mundo" (jederman, linha 122) que consta no poema de Sachs, é índice e fator do público do panfleto. ${ }^{12}$

No "Lamento dos selvagens", vem à tona a aliança e a divergência da Reforma e do Renascimento. A crítica que faz ao "mundo [tão] dissimulado/coberto de deslealdade e astúcia" (SACHS, linhas 97-98) é acessível ao "homem comum" e, portanto, a todos os estamentos que formavam o público da Reforma. Contudo, a Reforma como evento comunicativo de massa transpõe, mas não suspende hierarquias. Quando em 1523 Sachs tomou o partido de Lutero nas polêmicas religiosas através da publicação assinada do poema "Rouxinol de Wittenberg", houve protestos contra a petulância de um "sapateiro" se pronunciar sobre assuntos teológicos. Em 1549, o humanista Johann Cochläus indignavase porque "sapateiros e mulheres" debatiam as escrituras sagradas com

12 Sobre o "homem comum" como alocutor implícito ou explícito da literatura volante da Reforma, e o conteúdo empírico do topos tendo em vista a circulação dos folhetos, ver Giesecke (1991, p. 287). 
teólogos formados (KÖNNEKER, 1975, p. 149). Em 1527, o conselho da cidade de Nuremberg justificou a censura de uma publicação de Sachs afirmando que "não era seu ofício" (seynes ampts) compor livretos ou rimas contra a mais alta autoridade em Roma. O "Lamento dos selvagens" foi composto em 1530, logo após a proibição do conselho, quando Sachs voltou a se dedicar a temas mundanos. É significativo que, para protestar contra o mundo, Sachs se aproprie de um gênero cultivado por humanistas críticos do Catolicismo, mas não necessariamente adeptos do Protestantismo. 0 "elogio da selvageria" não só remete aos encômios

Luciana paradoxais, aos elogios da febre, da calvície, da selvageria; também lemVillas Bôas bra o mais paradoxal de todos os encômios, o Elogio da loucura de Erasmo, por ser o próprio objeto, a loucura em pessoa, o sujeto que fala.

Se no passado a erudição clássica de Sachs suscitou dúvidas, hoje todos concordam que o seu conhecimento literário abrangia desde autores clássicos e do renascimento italiano aos mais variados gêneros populares do vernáculo. A formação de Sachs é fruto "de leituras laboriosas, realizadas ao longo de décadas, admirável para um membro do seu estamento [...]" (KÖNNEKER, 1971, p. 5). A sua obra, tão rica e variada, é inseparável do centro intelectual, político, comercial e livreiro em que atuou: a cidade de Nuremberg.

\section{Todo mundo e os selvagens}

o lugar de impressão do panfleto, Nuremberg, é também um dos seus personagens. A literatura volante (Flugschriften), os folhetos avulsos e os panfletos (Flugblätter), impressos de uma página, eram recebidos pelo público da cidade, coletivamente, nas praças, tavernas, guildas, oficinas, feiras e igrejas. "Vendedores ambulantes, tão móveis quanto o meio de que faziam propaganda, encarregavam-se, junto com editores-impressores, contadores e agentes de arte, da venda, distribuição e circulação [de panfletos]." (MÜNKNER, 2008, p. 8). Em 1545, Nuremberg há muito se estabelecera como "um lugar independente de produção e recepção literária” (KLEINSCHMIDT, 1982, p. 91). Os panfletos eram impressos a custos baixos e em tiragens altas. Respondiam a uma demanda

13 "In der Fachnomenklatur gilt als Flugblatt das zumeist einseitig bedruckte Einzelblatt in verschiedenen Formatgrössen. [...] Obwohl die Forschung terminologisch nicht eindeutig zwischen 'Flugblatt' und 'Einblattdruck' unterscheidet [...] gehört es nach medientechnischen Gesichtspunkten zur Gattung des Einblattdrucks." (MÜNKNER, 2008, p. 8). Sobre a diferença entre literatura volante e panfletos, ver Nieden (2012, p. 6-11). Sobre os panfletos redigidos por Hans Sachs em adesão à Reforma, ver Bernd Balzer (1973). 
insaciável por novidade e disputavam um mercado cada vez mais diferenciado e competitivo (STRAUSS, 1966, p.152). A sua atração vinha da combinação simultânea de texto, imagem e manchete, da sua capacidade de prender a atenção, em um único lance, do seu espectador e potencial comprador. Eram "imagens-golpe" (Schlagbilder) (WOLFGANG HARMS apud MÜNKNER, 2008, p. 9), veículos preferenciais de catástrofes, prodígios, denúncias, milagres e polêmicas.

Repassemos as razões do apelo exercido pelos selvagens de $\mathrm{Nu}-$ remberg aventadas até aqui. Os selvagens diferenciam-se da figura tradicional do selvagem medieval. Diferenciam-se igualmente de ferozes, nus e canibais recém-descobertos. Não habitam um locus horridus nem os confins do mundo, vivem nos arredores da cidade, cercados por uma natureza amena. Têm família e o dom da linguagem. Vivem, no presente, conforme a Idade de Ouro. Comunicam ao público citadino o seu lamento contra mundum. Têm a função de espelho: as virtudes que encarnam denunciam os vícios da humanidade. Seguem o exemplo dos "germânicos" de Tácito, cuja simplicidade repreendia o luxo dos romanos, assim como os ancestrais de Celtis serviam de corretivo ao luxo itallico e aos alemães do presente. O pressuposto para essa função dos selvagens é a ressignificação da sua selvageria. E vice-versa. A circularidade da observação indica um aspecto estrutural do selvagem como instrumento de crítica cultural, esboça a selvageria como dispositivo discursivo. Para reaver a força dessa ressignificação do primitivismo, é preciso tentar especificar melhor o alvo e o meio da sua crítica.

Os selvagens especulares de Nuremberg divergem dos seus modelos passados e futuros por duas razões: pertencem ao mesmo mundo que o seu público; são exilados e asselvajados por opção. A sua selvageria não resulta da possessão de uma força diabólica ou da influência de um meio hostil, mas da regressão eletiva a um estado de pureza e simplicidade. É o exercício do livre-arbítrio que os leva a abandonar a sociedade, a adesão voluntária à simplicidade original. $\mathrm{O}$ que a existência fora dos muros da cidade oferece é nada mais nada menos do que o autogoverno. O primitivismo dos selvagens de Nuremberg coincide com reinvindicações protestantes, com o retorno ao cristianismo primitivo, a defesa do sacerdócio de todos os fiéis. A radicalidade do seu primitivismo como instrumento de crítica social é estar ao alcance de todos. O alocutor e o causador do lamento é "todo mundo" (jederman, SACHS, linha 122). O poema fecha em forma de exortação: somente 
quando se operar uma "mudança” (Enderung, SACHS, linha 120), quando "todo mundo" (jederman) for fiel e piedoso, os selvagens deixarão a floresta. Enuncia-se o paradoxo da selvageria como instrumento crítico: os selvagens deixarão de ser selvagens quando todos forem selvagens. A apreensão histórica do paradoxo não esvazia o potencial crítico da selvageria, antes expõe o elemento ficcional que a constitui. Os panfletos, hot media, tornam os selvagens acessíveis ao público como "espaços livres ideais" (ideelle Freiräume, KLEINSCHMIDT, 1982, p. 90).

Em que medida os selvagens de Nuremberg e outras partes par-

Luciana

Villas Bôas ticipam da transformação da esfera pública e da emergência das modernas noções de cultura e civilização é a indagação de que partiu no presente a nossa história.

\section{Klag der wilden Holzleut über die ungetrewen Welt}

1. Ach got, wie ist verderbt all welt, wie stark ligt die untreu zu felt, wie hart ist grechtigkeit gefangen, wie hoch tut ungrechtigkeit prangen, wie sitzt der wucherer in eren, wie hart kan arbeit sich erneren, wie ist gemeiner nutz so teuer, wie füllt der eigen nutz sein scheuer, wie nimt überhant die finanz, 10. wie spitzig ist der alefanz, wie unverschemt get gwalt für recht, wie hart die warheit wirt durchecht, wie wirt unschult mit füßen treten, wie weng tut man laster ausjeten, wie ring wigt man des menschen blut, wie gar helt man kein straf für gut, wie fürt reichtum so großen pracht, wie ist armut so gar veracht, wie stet weisheit hinder der tür, 20. wie dringt reichtum mit gwalt herfür, wie ist barmherzigkeit so krank, wie hat die lüg so weiten gank, wie regiert der neit mit gewalt, 
wie ist brüderlich lieb erkalt, wie ist die treu so gar erloschen, wie hat miltigkeit ausgedroschen, wie ist demut so gar verschwunden, wie hat der glaub so vil der wunden, wie ist gedult so gar gewichen, Os selvagens

30. wie ist frumkeit so gar erblichen, de Nuremberg wie ist die zucht so gar ein spot, e o seu wie ist keuschheit so ellent tot, wie ist einfalt so gar verdorben, lamento pela imprensa wie gar ist all freuntschaft gestorben, de 1545

wie ist leibes wollust so mechtig, wie ist hoffart so groß und prechtig,

wie herrscht schmeichlerei so gewaltig, wie ist nachred so manigfaltig, wie gern hört man neu märlein bringen, 40. wie ist betrug in allen dingen, wie ist die kunst so gar unwert, wie groß ist die torheit auf ert, wie findt man meßigkeit so selten, wie vil ist füllerei jezt gelten, wie hart muß sich der fridsam schmiegn, wie löblich ist mörden und kriegn, wie ist die eigen er so groß, wie ist der geiz so gar gruntlos, wie ist das spil so eigennützig, 50. wie gschicht die rauberei so trützig, wie ist der diebstal also grob, wie schwebt die listigkeit stets ob, wie ist gottes schweren so gmein, wie rechnet man meineit so klein, wie gar ist ebruch mer kein schant, wie fleischlich ist der geistlich stant, wie ist so blint die gleißnerei, wie wütig ist die tyrannei, wie ungezogen ist die jugent, 60. wie gar lebt das alter on tugent, wie unverschemt ist weiblich bilt, 
wie ist mänlich person so wilt, wie ist gesellschaft so untreu, wie hat borgen so vil nachreu, wie sint die war so gar vertrogn, wie sint die schult so gar verzogn, wie ist nachbaurschaft so geheßig, wie sint die wirtschaft so unmeßig, wie ro ist der menschen gewißen, 70. wie ist als unglück eingerißen,

Luciana Villas Bôas

146 wie tumb ist jezt die christenheit, wie selzam ist die heiligkeit, wie weng helt man gottes gebot, wie unbereit ist man zum tot, wie klein hat man auf ewigs acht, wie gar man auf das zeitlich tracht, wie unwirdig hört man gots wort, wie wenig lebt man darnach fort, wie ist all ding so gar verbittert, 80. mit trug und schalkheit übergittert! und in kurz, summa summarum, was in der welt ist schlecht und frum, muß von der welt durchechtet werden; was aber listig ist auf erden, verschalkt, vertrogen auf all ban, heißt die welt ein geschickten man. seit nun die welt ist so vertrogn, mit untreu, list ganz überzogn, so seien wir gangen daraus, 90. halten im wilden walde haus mit unsern unerzognen kinden, das uns die falsch welt nit mög finden, da wir der wilden frücht uns nern, von den würzlein der erden zern und trinken einen lautern brunnen. uns tut erwermen die liecht sunnen, mies, laub und gras ist unser gwant, darvon wir auch bet und deck hant; ein steine höl ist unser haus, 
100. da treibet keins das ander aus, unser gsellschaft und jubiliern

ist im holz mit den wilden tiern;

so wir denselben nichts nit tan,

laßens uns auch mit friden gan.

also wir in der wüsten sint,

Os selvagens

gebären kint und kindes kint.

de Nuremberg

einig und brüderlich wir lebn,

e o seu

kein zank ist sich bei uns begebn;

lamento pela

ein jedes tut, als es dan wolt,

imprensa

110. das im von jem geschehen solt;

de 1545

umb kein zeitliches tun wir sorgen,

unser speis find wir alle morgen,

nem wir zur notturft und nicht mer

und sagen got drumb lob und er.

fellt uns zu krankheit oder tot,

wiß wir, das es uns komt von got,

der alle ding am besten tut.

also in einfeltigem mut

vertreiben wir hie unser zeit,

120. bis ein enderung sich begeit

in weiter welte umb und um,

das jederman wirt treu und frum,

das stat hat armut und einfalt;

den wöll wir wider aus dem walt

und wonen bei der menschen schar.

wir haben hie gewart vil jar,

wenn tugnt und redlichkeit aufwachs.

das balt geschech, wünscht uns Hans Sachs.

Anno salutis 1530. am 2. tag Junij.

\section{Referências}

BALZER, Bernd. Bürgerliche Reformationspropaganda: Die Flugschriften des Hans Sachs in den Jahren 1523-25. Stuttgart: Metzler, 1973. 
BERNHEIMER, Richard. Wild men in in the Middle Ages: a study in art, sentiment and demonology. Harvard: Harvard University Press, 1952.

BENZING, Josef. Hans Guldenmund 1526-1560. Die Buchdrucker des 16. und 17. Jahhunderts im deutschen Sprachgebiet: 2 . verbesserte und ergänzte Auflage. Wiesbaden: Otto Harrassowitz, 1982. p. 356-357.

Luciana CROWTHER, Kathleen M. In his image and likeness: Adam and Villas Bôas Eve in the Refomation. Cambridge: Cambridge University Press, 2010. p. 52-98.

FALK, Tilam (Ed.); ZIJLMA, Robert (Comp.). Hans (Hans Leonhard) Schäufelein. Hollstein's German Engravings Etchings and Woodcuts 1400-1700. v. XLII, Gordian Sanz to Hans Schäufelein. Rotterdam: Sound \& Vision Interactive, [1954]1996. p. 83-234.

GIESECKE, Michael. Erste Schritte in der Technisisierung der öffentlichen Mahnung und Meinung. Der Buchdruck in der frühen Neuzeit: eine historische Fallstudie über die Durchsetzung neuer Informations - und Kommunikationstechonlogien. Frankfurt a. M.: Suhrkamp, 1991. p. 254-293. Disponível em: <https://www.uni-due. de/einladung/Vorlesungen/ausblick/giese_buchdr.htm>. Acesso em: 31 mar. 2014.

HUBER-REBENICH, Gerlinde. Neue Funktionen der Dichtung im Humanismus? In: MAISSEN, Thomas; WALTER, Gerrit (Ed.). Funktionen des Humanismus: Studien zum Nutzen des Neuen in der humanistischen Kultur. Göttingen: Wallstein Verlag, 2006. p. 49-75.

HUSBAND, Timothy. The wild men: Medieval myth and symbolism. New York: Metropolitan Museum of Art, 1980.

KIENING, Christian. Begehren. Das andere Selbst. Figuren des Todes an der Schwelle zur Neuzeit. Munique: Wilhelm Fink Verlag, 2003. p. 128-132. 
KLEINSCHMIDT, Erich. Literatur und städtische Gemeinschaft: Aspekte einer literarischen Stadtkultur in der Frühen Neuzeit. In: BRENNER, Horst (Ed.). Literatur in der Stadt. Göppingen: Kümmerle Verlag, 1982. p. 73-94.

KÖNNEKER, Barbara. Hans Sachs: Die Wittenbergisch Nachtigall Os selvagens und die Reformationsdialoge. Die Deutsche Literatur der Reformationszeit. Kommentar zu einer Epoche. Munique: Winkler Verlag, 1975. p. 148-156.

de Nuremberg e o seu lamento pela imprensa Hans Sachs. Stuttgart: Metzlerische Verlagsbuchhandlung, de 1545 1971.

KRAPF, Ludwig. Germanenmythus und Reichsideologie: Frühhumanistische Rezeptionsweisen der taciteischen "Germania". Tübingen: Max Niemeyer Verlag, 1979.

KREBS, Christopher B. Conrad Celtius: Vindikation der Germania und Rehabilitation Germaniens. Negotiatio Germaniae: Tacitus' Germania und Enea Silvio Piccolomini, Giannantonio Campano, Conrad Celtis und Heinrich Bebel. Göttingen: Vandenhoeck \& Ruprecht, 2005a. p. 190-225.

Tacitus' imagio Germaniae aus der Perspektive ihrer Wirkungsgeschichte: Negotiatio Germaniae: Tacitus' Germania und Enea Silvio Piccolomini, Giannantonio Campano, Conrad Celtis und Heinrich Bebel. Göttingen: Vandenhoeck \& Ruprecht, 2005b. p. 31-110.

A most dangerous book: Tacitus Germania from the Roman Empire to the Third Reich. New York: WW. Norton \& Company Inc., 2011.

LEITCH, Stephanie. Mapping etnography in early modern Germany: new worlds in print culture. New York: Palgrave Mcmillan, 2010. 
MÜNKNER, Jörn. Eingreifen und Begreifen: Handhabungen und Visualisierung in Flugblättern der Frühen Neuzeit. Berlin: Erich Schmidt, 2008.

NIEDEN, Marcel. Die Wittenberger Reformation als Medienereignis: Europäische Geschichte Online. 2012. Disponível em: <httpp://ieg.ego.eu/de/threds/europaeische-medienereignisse/ marcel-nieden-die-wittenberger-reformation-als-medienereignis>. Acesso em: 31 mar. 2014.

Luciana

Villas Bôas

RIDE, Jacques. L'image du germain dans la pensée et la litterature allemandes de la redecouverte de Tacitea la fin du XVIème siecle. Lille: Athelier Reproduction des Theses. Université de Lille II, Paris: Diffusion Librarie Honore Champion, 1977.

RUBIÉS, Joan-Pau. Ethnography, philosophy and the rise of natural man 1500-1750. In: ABBATTISTA, Guido (Ed.). Encountering otherness: diversities and transcultural experiences in Early Modern European Culture. Trieste: EUT Edizioni Università di Trieste, 2011. p. 97-127.

SACHS, Hans. Klagred der Welt ob ihrem verderben: Dagegen ein Straffred irer gruntlosen bossheit. Nuremberg: Johann Petreius, 1531. (New Haven: Beinecke Library, Zg16 Sa14 531k).

Klag der wilden Holzleüt über die ungetrewen Welt. Nuremberg: Hans Goldemundt, 1945. (Londres: British Museum, E, 8.1).

Eygentliche Beschreybung aller Stände auf Erden. Franckfurt am Meyn/ bey Georg raben/in verlegung Sigmund Feyerabends, M.D.LXVIII.

Klag der wilden holzleut uber die ungetrewen welt. In: VON KELLER, Adelbert (Ed.). Hans Sachs: Der dritt thail: von tugent und laster. Tübingen: Literarischer Verein in Stuttgart, 1870. v. 3, p. 561-564.

SCHMIDT, Susanne Karr. Art: a user's guide. Interactive and sculptural Printmaking in the Renaissance. Dissertation, Yale University, 2006. 
STRAUSS, Gerald. Nuremberg in the Sixteenth-Century. New York: Wiley, 1966.

STURTEVANT, William C. First visual images of Native America. In: CHIAPPELLI, Fredi et al. (Ed.). First images of America: the impact of the New World on the Old. Los Angeles: University of California Press, 1978. v. 1, p. 417-454.

Os selvagens de Nuremberg e o seu

TÁCITO. In: LUND, Allan A. P. (Ed.). Cornelius Tacitus Germania. lamento pela Interpretação, edição, tradução, comentário e bibliografia por Allan A. Lund. Heidelberg: Carl Winter Universitätsverlag, 1988. imprensa de 1545

WHITE, Hayden. The forms of wildness. Tropics of discourse. Baltimore: The Johns Hopkins University Press, 1978. p. 150-182.

WUTTKE, Dieter. Humanismus als integrative Kraft: die Philosophie des deutschen "Erzhumanisten" Conrad Celtis; eine ikonologische Studie zur programmatischer Graphik Dürers und Burgkmairs. Artibus et Historiae, v. 6, n. 11, p. 65-99, 1985. 
